\title{
Correction to: Long-term follow-up of a large cohort with focal epilepsy of unknown cause: deciphering their clinical and prognostic characteristics
}

\author{
Arife Çimen Atalar ${ }^{1,2}$ (D) $\cdot$ Ebru Nur Vanlı-Yavuz ${ }^{1,3} \cdot$ Ebru Yılmaz $^{4} \cdot$ Nerses Bebek $^{1} \cdot$ Betül Baykan $^{1}$
}

Published online: 26 December 2019

○) Springer-Verlag GmbH Germany, part of Springer Nature 2019

Correction to: Journal of Neurology https://doi.org/10.1007/s00415-019-09656-8

The original version of this article unfortunately contained a mistake. Affiliations of author were incorrect. The corrected affiliations are given below.

Arife Çimen Atalar ${ }^{1,2}$, Ebru Nur Vanl1-Yavuz ${ }^{1,3}$, Ebru Yılmaz $^{4}$, Nerses Bebek ${ }^{1}$, Betül Baykan ${ }^{1}$

${ }^{1}$ Departments of Neurology and Clinical Neurophysiology, Istanbul Faculty of Medicine, Istanbul University, Istanbul, Turkey

${ }^{2}$ Department of Neurology, Istanbul Education and Research Hospital, Istanbul, Turkey
The original article can be found online at https://doi.org/10.1007/ s00415-019-09656-8.

Arife Çimen Atalar

cimenatalar@yahoo.com.tr

1 Departments of Neurology and Clinical Neurophysiology, Istanbul Faculty of Medicine, Istanbul University, Istanbul, Turkey

2 Department of Neurology, Istanbul Education and Research Hospital, Istanbul, Turkey

3 Department of Neurology, Koc University Hospital, Istanbul, Turkey

4 Department of Nuclear Medicine, Istanbul Faculty of Medicine, Istanbul University, Istanbul, Turkey
${ }^{3}$ Department of Neurology, Koc University Hospital, Istanbul, Turkey

${ }^{4}$ Department of Nuclear Medicine, Istanbul Faculty of Medicine, Istanbul University, Istanbul, Turkey 